\title{
Use of Barium Chromate in Photocatalytic Degradation of Eosin Yellow
}

\author{
SANDHYA GUPTA, DIPTISONI, RAKSHITAMETA and SURBHI BENJAMIN* \\ Department of Chemistry, PAHER University, Udaipur-313003, Rajasthan, India \\ surbhi.singh1@yahoo.com
}

Received 25 May 2015 / Accepted 4 June 2015

\begin{abstract}
Environmental pollution is a big problem faced by everyone all over the world, out of which water pollution is a major one. In solving the problem of water pollution, photocatalysis plays an important role. In the present work, barium chromate powder has been used as a photocatalytst to degrade Eosin Yellow. The rate of decomposition was affected by different parameters such as $\mathrm{pH}$, concentration of dye, amount of photocatalyst and intensity of light. The optimum conditions were obtained as $\mathrm{pH}=7.5$, [Eosin Yellow] $=1.0 \times 10^{-5} \mathrm{M}$, amount of $\mathrm{BaCrO}_{4}=0.06 \mathrm{~g}$, light intensity $=$ $60.0 \mathrm{mWcm}^{-2}$. The rate constant obtained was $\mathrm{k}=1.53 \times 10^{-4} \mathrm{sec}^{-1}$. The reaction proceeded through oxidation by hydroxyl radicalas confirmed by radical scavenger 2-propanol.
\end{abstract}

Keywords: Photocatalytic, Eosin Yellow, Barium chromate

\section{Introduction}

Today mankind is facing water scarcity and water pollution as a major threat. According to the World Health Organization (WHO), the shortage of water affects more than $40 \%$ of the world population and more than $25 \%$ of the world population suffers from health and hygienic problems related to water. Most of the water related diseases are caused by the contamination of water. The chief pollutants are chlorinated organic derivatives, chlorinated solvents, nitro derivatives of benzene and phenol, pesticides like triazine derivatives and azodye derivatives. Most of these compounds are not degraded by direct exposure to sunlight since their absorption rate in the visible range is very less. Moreover majority of these compounds are stable and can persist for sufficiently long time. One of the technique of removal of these contaminants is by degradation of dyes by using semiconductor photocatalysts (such as $\mathrm{TiO}_{2}, \mathrm{ZnO}, \mathrm{CdS}, \mathrm{BaCrO}_{4}$, etc.), but most of these photocatalysts work under UV light,which restricts their applications in sunlight since sunlight that reaches the Earth's surface contains only 4\% UV light. There are few catalysts that are active under visible light, but their efficiency is low due to fast charge recombination. Hence, the main challenge among the scientists is to search newer materials or to reduce that recombination time ${ }^{1-3}$. Among these materials, $\mathrm{BaCrO}_{4}$ (also called Hashemite) with a band gap of $2.63 \mathrm{eV}$ is an attractive candidate for photocatalysis ${ }^{4}$. 
$\mathrm{BaCrO}_{4}$ is a chromate analog of barite, which is mostly used as an oxidizing agent in organic reaction. $\mathrm{BaCrO}_{4}$ was used as photocatalyst in the degradation of methylene blue dye and mineralization of azure $\mathrm{B}^{5}$. The disappearance of the dye has been observed using spectrophotometer which followed pseudo first order kinetics according to LangmuirHinshelwood model. Therefore, considering a safe and cost-effective photocatalyst in the visible region with enhanced activity, current techniques such as doping and composite formation are used. One challenge is to use graphene, a two-dimensional (2D) carbon nanostructure, as conductive carbon mats to anchor photocatalytic materials to form new composite hybrid materials with potential application in optoelectronics and energy conversion devices ${ }^{6-9}$.

Li et al., ${ }^{10}$ investigated the photodegradation of methylene blue using the $\mathrm{TiO}_{2} / \mathrm{Ti}$ electrode under different experimental conditions in presence of UV. Chemical oxygen demand (COD) removal was also studied. The prepared electrode mainly consisted of anatase $\mathrm{TiO}_{2}$ nanoparticles on its surface and exhibited a superior photocatalytic activity. The COD removal during the photodegradation of methylene blue by $\mathrm{TiO}_{2} / \mathrm{Ti}$ mesh electrode was $97.3 \%$.

Pereira et al., ${ }^{11}$ studied that degradation of two xanthene dyes, Erythrosine B (Ery) and Eosin Y (Eos), using UV/titanium dioxide in a photocatalytic reactor. Photocatalysis was able to degrade $98 \%$ of Ery and $73 \%$ of Eos and results in removal of $65 \%$ chemical oxygen demand. It was revealed that it is a $\mathrm{pH}$ dependent process and better results were obtained under acidic conditions, which may be due to the electrostatic attraction caused by the opposite charges of $\mathrm{TiO}_{2}$ (positive) and anionic dyes (negative).

Byberg et al., ${ }^{12}$ studied the photocatalytic degradation of a series of six acid dyes (Direct red 80, Direct red 81, Direct red 23, Direct violet 51, Direct yellow 27 and Direct yellow 50), which was compared in terms of color removal, mineralization and toxicity (Lactuca sativa L. test) after photocatalysis on immobilized titanium dioxide. Chakrabarti and Dutta ${ }^{13}$ have explored the potential of a common semiconductor, $\mathrm{ZnO}$ as an effective catalyst for the photodegradation of two model dyes, methylene blue and Eosin Y. A 16 W lamp was used as the source of UV-radiation in a batch reactor. Substantial reduction of COD and removal of colour was also observed.

Eosin $Y$-sensitized TS-1 zeolite was studied for the photo-reduction of water into hydrogen driven by visible light $(\lambda \geq 420 \mathrm{~nm})$. The optimum $\mathrm{pH}$ and weight ratio between eosin Y and TS-1 zeolite is 7 and $1 / 8$, respectively. In the presence of triethanolamine (TEA) as an electron donor, the highest rate of hydrogen generation and apparent quantum efficiency are $34 \mu \mathrm{mol} \mathrm{h}^{-1}$ and $9.4 \%$, respectively, under visible light irradiation $(\lambda \geq 420 \mathrm{~nm})$. Short-term stability test indicates that the catalyst is rather stable during $50 \mathrm{~h}$ photoreaction $^{14}$.

$\mathrm{Bi}_{2} \mathrm{O}_{3}$-Ruduced graphene oxide (RGO) composite with 2 wt. $\%$ RGO achieves maximum methyal orange and methylene blue degradation rates of $93 \%$ and $96 \%$ at 240 min. under visible light irradiation, respectively, much higher than those for the pure $\mathrm{Bi}_{2} \mathrm{O}_{3}(78 \%$ and $76 \%$ ). The enhanced photocatalytic performance is ascribed to the increased light adsorption and the reduction in electron-hole pair recombination in $\mathrm{Bi}_{2} \mathrm{O}_{3}$ with the introduction of $\mathrm{RGO}$ by $\operatorname{Liu} \mathrm{X}^{15}$.

The photocatalytic activity of $\mathrm{Bi}_{2} \mathrm{O}_{3}$ for the treatment of phenolic wastes have been studied by Reddy et al., ${ }^{16}$. Panwar et al., ${ }^{17}$ observed the degradation of some dyes using zirconium phosphate photocatalyst. Kothari et al., ${ }^{18}$ worked on the photoreduction of Congo red by ascorbic acid and EDTA over cadmium sulphide as photocatalyst. 


\section{Experimental}

Eosin yellow is a red yellow fluorescence dye with slightly acidic nature. It is soluble in water. Eosin $\mathrm{Y}$ is an organic compound with the molecular formula $\mathrm{C}_{20} \mathrm{H}_{6} \mathrm{Br}_{4} \mathrm{Na}_{2} \mathrm{O}_{5}$ and its IUPAC name is 2-(2,4,5,7-tetrabromo-6-oxido-3-oxo-3H-xanthen-9-yl)benzoate. It is also known as Eosin yellowish (Scheme 1), Eosin Y, Eosine, Bromofluorescein, Eosine Yellowish, Eosine $\mathrm{G}$ with molecular weight $691.854179 \mathrm{~g} / \mathrm{mol}$. It is used in cosmetics, pharmaceuticals, textiles dyeing and ink manufacturing as biological stain, vital stain and counter stain with hematoxylin. It is also used in special culture media.

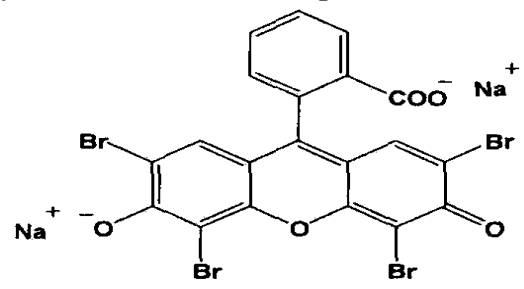

Scheme 1. Structure of Eosin yellow

$0.0692 \mathrm{~g}$ of Eosin yellow was dissolved in $100 \mathrm{~mL}$ doubly distilled water so as make that the concentration of dye solution $1.0 \times 10^{-3} \mathrm{M}$. It was used as a stock solution. $0.06 \mathrm{~g}$ barium chromate was added, $\mathrm{pH}$ was adjusted to 7.5 and it was exposed to a light of $60.0 \mathrm{mWcm}^{-2}$. The absorbance of Eosin yellow solution was determined with the help of a spectrophotometer at $\lambda_{\max }=510 \mathrm{~nm}$. The dye solution was divided in four beakers.

1 First beaker containing Eosin yellow solution was kept in dark.

2 Second beaker containing Eosin yellow solution was exposed to light.

$30.06 \mathrm{~g}$ barium chromate was added to the third beaker containing Eosin yellow solution and was kept in dark.

$40.06 \mathrm{~g}$ barium chromate was added to the fourth beaker containing Eosin yellow solution and was exposed to light.

These beakers were kept for 3-4 hours and then the absorbance of each solution was measured with the help of a spectrophotometer (Systronics Model 106). It was observed that the absorbance of solutions of first three beakers remained virtually constant, while the solution of fourth beaker showed reasonable decrease in its initial value. This observation suggests that this reaction requires both; the presence of light as well as semiconductor barium chromate. Therefore, this reaction is a photocatalytic reaction in nature and it is not chemical (thermal) or photochemical type of reaction.

\section{Results and Discussion}

A solution of $1.0 \times 10^{-5} \mathrm{M}$ Eosin yellow was prepared in doubly distilled water and $0.06 \mathrm{~g}$ of barium chromate was added to it. The $\mathrm{pH}$ of the reaction mixture was adjusted to 7.5 and then this solution was exposed to a $200 \mathrm{~W}$ tungsten lamp at $60.0 \mathrm{Wcm}^{-2}$. It was observed that there was a decrease in absorbance of Eosin yellow solution with increasing time of exposure. A linear plot between $1+\log$ (optical density) vs. time was obtained, which indicates that the photocatalytic degradation of eosin yellow follows pseudo-first order kinetics according to Langmuir-Hinshelwood model. The rate constant for this reaction was measured by the following expression:

$$
\text { Rate constant }(\mathrm{k})=2.303 \times \text { slope }
$$

The data of typical run has been presented in Table 1 and graphically in Figure 1 . 
Table 1. A typical run [Eosin yellow] $=1.0 \times 10^{-5} \mathrm{M} \mathrm{pH}=7.5$ Light Intensity $=60.0 \mathrm{mWcm}^{-2}$ $\mathrm{BaCrO}_{4}=0.06 \mathrm{~g} \mathrm{k}=1.53 \times 10^{-4} \mathrm{~s}^{-1}$

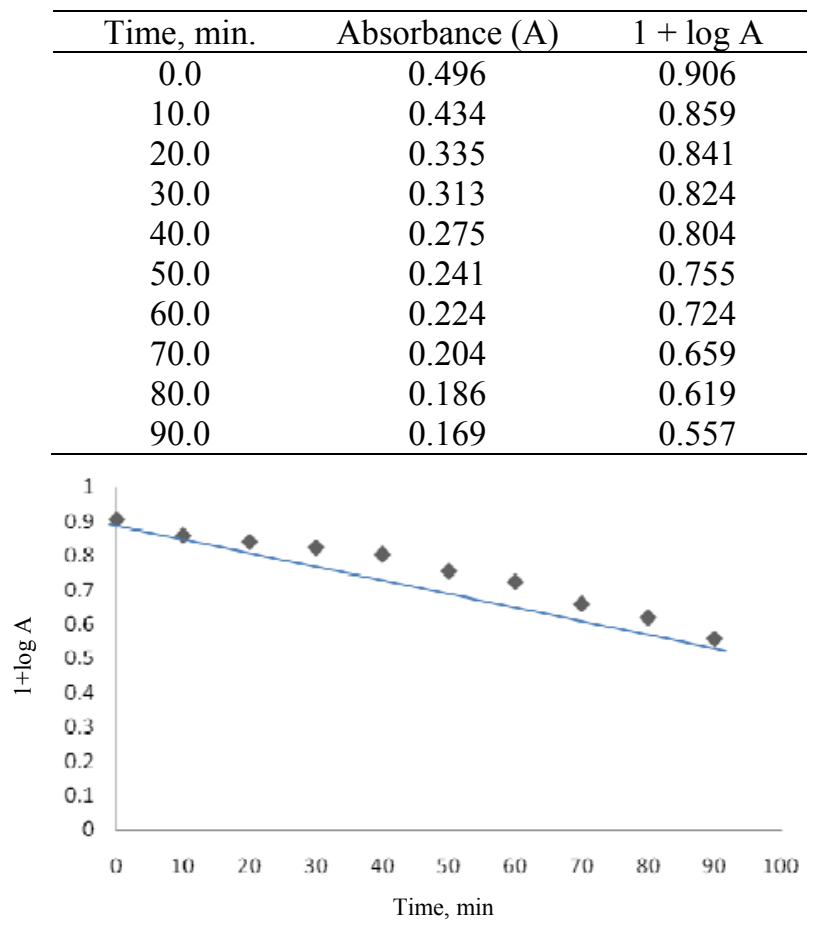

Figure 1. Typical run

Different rate affecting parameters were studied to get the optimum rate for degradation of dye including $\mathrm{pH}$, concentration of dye, amount of semiconductor and light intensity.

\section{Effect of $p H$}

The effect of $\mathrm{pH}$ on photocatalytic degradation was investigated. The reaction rates were determined in different $\mathrm{pH}$ range from 5.0-10.0. The results are tabulated in Table 2.

Table 2. Effect of $\mathrm{pH}$ [Eosin yellow $]=1.0 \times 10^{-5} \mathrm{M} \mathrm{BaCrO}_{4}=0.06 \mathrm{~g}$ Light Intensity $=$ $60.0 \mathrm{mWcm}^{-2}$

\begin{tabular}{|c|c|}
\hline $\mathrm{pH}$ & $\mathrm{k} \times 10^{4}, \mathrm{~s}^{-1}$ \\
\hline 5.0 & 0.63 \\
\hline 5.5 & 0.70 \\
\hline 6.0 & 0.76 \\
\hline 6.5 & 0.88 \\
\hline 7.0 & 1.04 \\
\hline 7.5 & 1.53 \\
\hline 8.0 & 1.14 \\
\hline 8.5 & 0.85 \\
\hline 9.0 & 0.69 \\
\hline 9.5 & 0.57 \\
\hline 10 & 0.38 \\
\hline
\end{tabular}


It has been observed that the rate of photocatalytic degradation of Eosin yellow degradation of increases as $\mathrm{pH}$ was increased and it attained optimum value at $\mathrm{pH}$ 7.5. On further increasing $\mathrm{pH}$, the rate of the reaction was decreased. This behavior may be explained on the basis that as $\mathrm{pH}$ was increased, there is greater probability for the formation of hydroxyl radicals, which are produced from the reaction between ${ }^{-} \mathrm{OH}$ ions and hole $\left(\mathrm{h}^{+}\right)$ in valence band of the semiconductor. With the formation of more ${ }^{\circ} \mathrm{OH}$ radicals, the rate of photocatalytic degradation of the dye increases. Above $\mathrm{pH} \mathrm{7.5,} \mathrm{a} \mathrm{decrease} \mathrm{in} \mathrm{the} \mathrm{rate} \mathrm{of}$ photocatalytic degradation of the barium chromate was observed, which may be due to the fact that semiconductor surface becomes negatively charged by the adsorption of $\mathrm{OH}^{-}$ions which now does not attract the anionic dye.

\section{Effect of eosin yellow concentration}

The effect of dye concentration was studied by taking different concentrations of Eosin yellow. The results are tabulated in Table 3 .

Table 3. Effect of eosin yellow concentration Light Intensity $=60.0 \mathrm{mWcm}^{-2}$ $\mathrm{pH}=7.5 \mathrm{BaCrO}_{4}=0.06 \mathrm{~g}$

\begin{tabular}{cc}
\hline [Eosin yellow ] $\times 10^{5} \mathrm{M}$ & $\mathrm{k} \mathrm{x} 10^{4}\left(\mathrm{~s}^{-1}\right)$ \\
\hline 0.8 & 0.97 \\
0.9 & 0.97 \\
1.0 & 1.53 \\
1.1 & 0.88 \\
1.2 & 0.65 \\
1.3 & 0.63 \\
1.4 & 0.60 \\
1.5 & 0.52 \\
\hline
\end{tabular}

From the above data, it was observed that the rate of photocatalytic degradation of dye increases with increasing the concentration of Eosin yellow up to $1.0 \times 10^{-5} \mathrm{M}$. It may be attributed to the fact that as the concentration of the Eosin yellow was increased, more dye molecules were available for excitation followed by consecutive energy/electron transfer and hence there was an increase in the rate. The rate of degradation was found to decrease with an increase in the concentration of dye above $1.0 \times 10^{-5} \mathrm{M}$. This may be because of the fact that after a particular concentration, the dye may start acting as an internal filter and it will not permit the sufficient light intensity to reach surface of the photocatalyst at the bottom of reaction vessel and there by deceasing the rate of photocatalytic degradation of eosin yellow.

\section{Effect of amount of semiconductor}

The effect of amount of semiconductor on the rate of photocatalytic removal of Eosin yellow was also observed by taking different amounts of barium chromate. The results are tabulated in Table 4.

It was observed that the rate of reaction was found to increase on increasing the amount of semiconductor, barium chromate. The rate of degradation reached to its optimum value at $0.06 \mathrm{~g}$ of the photocatalyst. Beyond $0.06 \mathrm{~g}$, the rate of reaction becomes almost constant. This may be due to fact that as the amount of semiconductor was increased, the exposed surface area also increases. However, after a particular value $(0.06 \mathrm{~g})$, an increase in the amount of semiconductor will only increase the thickness of layer of the semiconductor and not its exposed surface area. This was confirmed by taking reaction vessels of different sizes. It was observed that this point of saturation was shifted to a higher value for vessels of larger volumes while a reverse trend was observed for vessels of smaller capacities. 
Table 4. Effect of amount of barium chromate [Eosin yellow] $=1.0 \times 10^{-5} \mathrm{M} \mathrm{pH}=7.5$ Light Intensity $=60.0 \mathrm{mWcm}^{-2}$

\begin{tabular}{|c|c|}
\hline Amount of Semiconductor, $g$ & $\mathrm{k} \times 10^{4}, \mathrm{~s}^{-1}$ \\
\hline 0.02 & 0.90 \\
\hline 0.04 & 0.99 \\
\hline 0.06 & 1.53 \\
\hline 0.08 & 1.52 \\
\hline 0.10 & 1.53 \\
\hline 0.12 & 1.54 \\
\hline 0.14 & 1.55 \\
\hline 0.16 & 1.56 \\
\hline
\end{tabular}

\section{Effect of light intensity}

The effect of variation of light intensity on the photocatalytic degradation of eosin yellow was also investigated. The light intensity was varied by changing the distance between the light source and the exposed surface area of semiconductor. The results are tabulated in Table 5.

Table 5. Effect of light intensity [Eosin yellow] $=1.0 \times 10^{-5} \mathrm{M} \mathrm{pH}=7.5 \mathrm{BaCrO}_{4}=0.06 \mathrm{~g}$

\begin{tabular}{cc}
\hline Light Intensity, $\mathrm{mW} \mathrm{cm}^{-2}$ & $\mathrm{k} \mathrm{X10}^{4}, \mathrm{~s}^{-1}$ \\
\hline 20 & 0.51 \\
30 & 0.71 \\
40 & 0.87 \\
50 & 1.20 \\
60 & 1.53 \\
70 & 1.34 \\
\hline
\end{tabular}

The results indicate that photocatalytic degradation of Eosin yellow was enhanced with the increase in intensity of light, because an increase in the light intensity will increase the number of photons striking per unit area per unit time of photocatalyst surface. There was a light decrease in the rate of reaction as the intensity of light was increased beyond $60.0 \mathrm{mWcm}^{-2}$. Therefore, light intensity of medium order was used throughout the experiments.

\section{Mechanism}

On the basis of these observations, a tentative mechanism for photocatalytic degradation of eosin yellow dye has been proposed as follows:

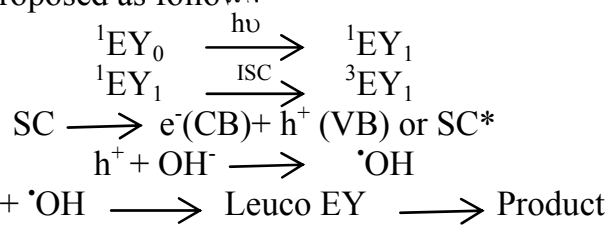

Eosin yellow (EY) absorbs radiations of suitable wavelength and it is excited giving its first excited singlet state followed by intersystem crossing (ISC) to give its more stable triplet state. Along with this, the semiconducting barium chromate (SC) also utilizes this energy to excite its electron from valence band to the conduction band. An electron can be abstracted from hydroxyl ion by hole $\left(\mathrm{h}^{+}\right)$present in the valence band of semiconductor generating $\bullet \mathrm{OH}$ radical. This hydroxyl radical will oxidize eosin yellow to its leuco form, which may ultimately degrade to products. It was confirmed that the ${ }^{\circ} \mathrm{OH}$ radical participates 
as an active oxidizing species in the degradation of Eosin yellow as the rate of degradation was appreciably reduced in presence of hydroxyl radical scavenger (2-propanol).

\section{Conclusion}

In the present work, a ternary semiconductor i.e. barium chromate is successfully used as a photocatalyst for degradation of eosin yellow, which explore its use for removal of a variety of industrial effluents in future.

\section{References}

1. Rehman S, Ullah R, Butt A M and Gohar N D, J Hazard Mater., 2009, 170(2-3), 560-569; DOI:10.1016/j.jhazmat.2009.05.064

2. Yang J L, An S J, Park W L, Yi G C and Choi W, Adv Mater., 2004, 16(18),16611664; DOI:10.1002/adma.200306673

3. Liu X, Pan L, Lv T, Zhu G, Sun Z and Sun C, Chem Comm., 2011, 47(43), 11984 11986; DOI:10.1039/C1CC14875C

4. Thakare S R, Patil S R and Choudhary M D, Indian J Chem Sect A, 2010, 49, 54-58.

5. Pare B, Singh V and Jonnalagadda S B, Indian J Chem Sect., 2011, 50A(8), 1061-1065.

6. Huang X, Qi X, Boeyab F and Zhang H, Chem Soc Rev., 2012, 41(2), 666-686; DOI:10.1039/C1CS15078B

7. Rao C N R, Sood A K, Subrahmanyam K S and Govindaraj A, Angew Chem Int Ed., 2009, 48(42), 7752-7777; DOI:10.1002/anie.200901678

8. Manga K K, Zhou Y, Yan Y L and Loh K P, Adv Funct Mater., 2009, 19(22), 36383643; DOI:10.1002/adfm.200900891

9. Guo C X, Yang H B, Sheng Z M, Lu S Z, Song Q L and. Li C M, Angew Chem Int Ed., 2010, 49(17), 3014-3017; DOI:10.1002/anie.200906291

10. Li J, Zheng L, Li L, Xian Y Jin L, J Hazard Mater., 2007, 139(1), 72-78;

DOI:10.1016/j.jhazmat.2006.06.003

11. Pereira L, Pereira R, Oliveira C S and Apostol L, Gavrilescu M, Pons M N, Zahraa O and Alves M M, Photochem Photobiol., 2013, 89(1), 33-39; DOI:10.1111/j.17511097.2012.01208.x

12. Byberg R, Cobb J, Martin L D, Thompson R W, Camesano T A, Zahraa O and Pons M N, Environ Sci Pollut Res Int., 2013, 20(6), 3570-3581; DOI:10.1007/s11356-013-1551-y

13. Chakrabarti S and Dutta B K, J Hazard Mater., 2004, 112(3), 269-278; DOI:10.1016/j.jhazmat.2004.05.013

14. Zhang X, Jin C Z, Li Y, Liand S and Lu G, Appl Surface Sci., 2008, 254(15), 44524456; DOI:10.1016/j.apsusc.2008.01.038

15. Liu X, Pan L, Lv T, Sun Z and Sun C Q, J Colloid Interface Sci., 2013, 408(15), 145150; DOI:10.1016/j.jcis.2013.07.045

16. Reddy J K, Lalitha K, Kumariand V D and Subrahmanyam M, Catal Lett., 2008, 121(2), 131-136; DOI:10.1007/s10562-007-9309-0

17. Panwar O P, Kumar A, Ametaand R and Ameta S C, Mac J Chem Engg., 2008, 27(2), 133-139.

18. Kothari S, Kumar A, Vyas R, Ameta R and Punjabi P B, J Braz Chem Soc., 2009, 20(10), 1821-1826; DOI:10.1590/S0103-50532009001000008 